\title{
VIEWPOINT
}

\section{The great badgers and bovine TB debate}

\author{
M. HANCOX \\ 17 Nouncells Cross, Stroud, Gloucestershire GL5 1PT, UK
}

(MS received 1 March 2002)

\begin{abstract}
Progress in politics and science often happens by serendipity, and an unforeseen effect of the 2001 foot and mouth epidemic will be its impact on bovine tuberculosis in three areas. Cattle TB will be much worse, increasing the risk to public health, and 'the highly emotive and complex issue' of badgers and TB may be resolved after 30 years controversy. A critical reappraisal of these three areas is worthwhile.
\end{abstract}

\section{THE CATTLE TB CRISIS}

A critical reappraisal of cattle TB schemes over the last century worldwide suggests that success requires two elements: annual testing of all cattle and, since the skin test is only $80 \%$ accurate, a movement ban into TB-free areas, the only way to guarantee preventing the spread of TB via 'missed' or untraced carriers (Hancox $2000 a, b)$. It takes a year or so for cattle to reach the more infectious reactor stage (McIlroy et al. 1986; Neill et al. 1988; White \& Griffin 1997). That is why annual testing is the gold standard worldwide and under EC Directives, because it has seven main effects on transmission: cattle may be removed before they can pass on $\mathrm{TB}$ to any extent within the herd, time to achieve clear tests is reduced, spread to contiguous herds is minimized and detected more rapidly, export of 'latent carriers' is minimized and any cases are picked up more quickly, and fewer cases reach the 'sputum positive' infectious stage with overt lung lesions. For example, only one in five such reactors were found in two Ulster studies (McIlroy et al. 1986; Neill et al. 1988). This incidentally is why abattoir meat inspection ensures safety (White $\&$ Griffin 1997). Annual testing hence permits the removal of TB cases as they come 'on stream' as infectious reactors, and sustained intensive widespread testing will gradually weed out all TB carriers. Cattle TB schemes go wrong when a premature relaxation of the twin controls allows the 'undisclosed reservoir' to escape from containment (Hancox $2000 a, b$ ). Britain had a textbook scheme which achieved a low point by 1979 of 89 herds and 600 cases mostly in tiny southwest 'hotspots'. The Ministry of Agriculture (MAFF) were overstretched at the height of BSE in 1992-93 with 36000 BSE cases a year. Longer test intervals came in with fewer cattle TB tested and this together with massive stock replacement movements, resulted in a doubling of TB in southwest herds from 121 to 232. More reactors per breakdown took longer to clear-test and the start of new hotspot clusters on Exmoor, followed by Hereford/Worcester, then subsequently Derbyshire/Staffordshire and Cheshire/ Shropshire. With no TB testing for 10 months due to foot and mouth, TB may well have doubled again from the 2000 levels of 1031 herds and 9000 cases, which is a slippage to 1960s levels (Zuckerman 1980). TB was taken to Cheshire/Lancashire in restocking after the 1967 foot and mouth disease, and cases have already appeared in Cumbria and SW Scotland. Sadly, there are to be no movement bans for $98.5 \%$ of herds, and few extra resources to clear the back$\log$ of some $26000 \mathrm{~TB}$ tests. It will take a year to restore 'normality', quite apart from introducing some annual test parishes in staggered fashion in 2-4 year test interval areas which are effectively now $3-5$ yearly.

\section{RISK TO PUBLIC HEALTH}

Usually the first measure countries take when launching cattle TB schemes is a mandatory ban on unpasteurized milk, as in Ireland and Scotland. Such a ban has been thwarted politically in England and Wales up to now (Hancox 1998; Dormandy 1999). The last case from milk was in 1959 in schoolchildren in Yorkshire (Hardie \& Watson 1992). But with TB now spreading widely in the southwest and into Midlands areas which have been TB-free for 40 years, and with the slippage in testing, there must be an increased risk, with two farmer cases in 1999. Farmers continue to drink their own home product unpasteurized. Some 400 'greentop' milk producers are under stricter annual testing and labelling measures but, with TB so widely spread now, this may not be enough. It is a nice irony that, as long ago as 1847 , The Lancet warned that it was difficult to find milk in London not contaminated with pus or blood which might be linked to scrofula (a cervical lymphadenitis). Koch discovered the tubercle bacillus in 1882, but then suggested bovine TB was not a risk to man, an error 
which a Royal Commission took 15 years to rectify (Francis 1947). Pioneers such as Bang, Ostertag and $\mathrm{McF}$ adyean were recommending pasteurization pre-1900, yet there were 2000 human deaths annually from bovine TB in the 1930s when $8 \%$ of milk was infected (Hancox $2000 c$ ). With the rise of other milkborne pathogens such as Escherischia coli, Salmonella, campylobacter and Mycobacterium avium ssp., Paratuberculosis linked to bowel disease (Crohns in humans, Johnes in cattle), the Advisory Committee on the Microbiological Safety of Foods has been urging mandatory pasteurization since 1995 (DL Georgala, personal communication). With some $2 \%$ of milk infected, and not necessarily sterilized by $15 \mathrm{~s}$ of heat treatment, $90 \%$ of human sufferers carry the MAP bacilli which do respond to anti-mycobacterials (Hancox $2000 c$ ).

The Food Standards Agency is also looking at meat safety, but cooking and abattoir inspection measures would seem to be adequate and have already been exhaustively reviewed (Francis 1947; Collins 1997). Annual testing is the gold standard worldwide and under EC Directives because it removes reactors before they get to the advanced lesion and hence more infectious stages, hence minimizing TB spread within and between herds, as well as being the scientific basis for partial or total condemnation of carcasses at abattoir inspection. It is also a safeguard for abattoir staff (O'Reilly \& Daborn 1995; Collins 1997; White \& Griffin 1997).

One aspect of the recent review of badgers and bovine tuberculosis was to assess risks to public health in the light of EC Directives (Krebs 1997). This has resulted in greater liaison between health and veterinary authorities, but the rise in cattle TB may force a further rethink.

\section{THE BADGER CULLING TRIAL COMPROMISED}

Badgers have been increasingly blamed for the failure of the GB cattle TB scheme since 1971; there being four claims in support of and justifying badger culling:

1. the intractable 'southwest problem area' with a high density badger population;

2. badgers cause $80-90 \%$ of cattle herd breakdowns (Krebs 1997);

3. transmission is one way, from badger to cattle (Zuckerman 1980; Dunnet et al. 1986; and modelling (below));

4. badger culls "work in preventing further herd breakdowns' (Krebs 1997).

In fact, the Krebs review (1997) admitted that it is not known if, how or to what extent badgers might realistically give cattle a respiratory lung infection, or whether culls work. Furthermore, the badger culling trial attempts to answer these two questions (Bourne 2001). None of the four claims stand up to scrutiny, and reappraisal of cattle TB schemes in the light of BSE and FMD destroys the rationale behind badger culling. The two main flaws are that there has been an 'undisclosed reservoir' of cattle TB present all along and that transmission from cattle to badger is the simplest explanation for the epidemiological patterns seen.

Britain's cattle TB scheme had brought TB down to relic southwest hotspots by the early 1970s before any badger culling had started in 1975. Sustaining the TB controls would have achieved eradication with even west Penwith, Cornwall, clear by 1985. Furthermore, intensified synchronized testing of chronic herd clusters were succeeding as in Steeple Leaze, Dorset (Little et al. 1982). The advent of BSE and now FMD has simply allowed the 'undisclosed reservoir' to grow and escape from containment, such that by 1999 over $50 \%$ of breakdowns were in areas TB-free for 10 years: 15 out of 25 in Avon, 103 in 139 in Cornwall, 54 in 99 in Devon and even more in 'frontier' counties: 6 in 6 in Derbyshire, 4 in 5 in Shropshire and 29 in 30 in Staffordshire (Hancox $2000 a, b$ ). This spread puts the 'southwest problem area' into perspective, and has not been prevented by some 25 years of badger culling. With respect to the five proven cases of badger culls working: (1) the 1975-76 drop in cattle TB was more to do with banning Irish imports - Ireland also showed a drop due to climatic factors which was nothing to do with culls (Dunnet et al. 1986; McInerney $1987 a, b)$; (2) Steeple Leaze, Dorset as well as (3) Hartland, Devon and (4) Thornbury, Avon were merely synchronized intensive testing, the latter 'proof' explicitly disregarded contiguous spread and the up to $70 \%$ of latent carriers (Clifton-Hadley et al. 1995); (5) Offaly, Ireland: it seems rather absurd to claim that culling 148 TB badgers from $600 \mathrm{~km}^{2}$ in $1988-94$ was significant relative to removing 1428 reactors from 55000 cattle in this area compared with 5216 from 150000 cattle in the control area, i.e. similar reactor rates (Hancox $2000 a, b)$.

In attributing source of TB in herd breakdowns, the protocols (Zuckerman 1980; Krebs 1997) fail to recognize the seemingly non-reactor and noninfectious 'undisclosed source', so that badgers get blamed by default. Other wildlife or domestic animal or human sources are improbable (Hancox 1999), and the 'due to badgers' breakdowns were originally given as 'unknown' source, e.g. $69 \%$ in Cornwall 1972-78 or $32 \%$ in Ulster currently even with a fully computerized cattle database. Lastly, since it is claimed that both cattle and badger TB is of some $80 \%$ respiratory origin it is hard to see how transmission could occur in either direction; mutual avoidance! The misunderstanding arises through failing to recognize that lung TB in badgers is secondary, TB often first being 
shown to be of dietary origin in the submandibular lymph nodes under the tongue (Little et al. 1982; Anderson \& Trewhella 1985; Pritchard et al. 1986; Hancox 1995, 1997, 1999). The distinction between primary and secondary lung infection is clear (Francis 1947, 1958), but uncritical studies of badger lesions have perpetuated the error (Krebs 1997; Gallagher \& Clifton-Hadley 2000; O’Boyle 2000).

The four claims as to 'badger guilt' are hence illfounded; and badger culling is unjustifiable on four main grounds:

(1) The science is flawed. The real problem with cattle TB is the undisclosed reservoir which requires better tests and traceability. The Bovigam interferon test is better at picking up early cases in problem herds or areas in Ireland and New Zealand (White \& Griffin 1997; Collins 1997). Spillover of TB from cattle to badgers is far more credible than vice versa, and has recently been demonstrated in the MAFF Woodchester study. Only some six clans were affected until the 1987-89 herd breakdowns when three new clans were affected and others since (Wilesmith 1991; Krebs 1997; Delahay et al. 2000). Computer simulation models based on Woodchester high density badger populations assume there is no spillover from cattle yet note high TB levels in badgers after bad herd breakdowns: $65 \%$ Exmoor, $70 \%$ Hereford/ Worcester (Anderson \& Trewhella 1985; Bentil \& Murray 1993; Smith et al. 1995, 1997, $2001 a$, $b$; White \& Harris $1995 a, b$; Ruxton 1996; Swinton et al. 1997; White et al. 1997; Tuyttens \& MacDonald 1998; Woodroffe et al. 1999; Delahay et al. 2000; Tuyttens et al. 2000; Smith 2001). Models of culling, vaccination or fertility control are hence compromised. The validity of the Krebs/Bourne trial has been further compromised by non-cooperation of farmers, loss of 135 herds in trial areas to FMD, trap interference as in Sussex (Pritchard et al. 1986) and the database swamped by FMD effects (Hancox 1998).

(2) Ethical. Badgers are legally protected (1992 Act and Bern Convention) and the closed season meant to protect lactating sows and cubs is too short (Bourne 2001).

(3) Economic. Badger culls are labour intensive and can never be cost-effective (Dunnet et al. 1986; McInerney $1987 a, b)$. Each TB badger so far has cost $£ 35000$.

(4) Political. Badger culls do not work and are a waste of money. So "In the last analysis the problem of badgers and bovine tuberculosis is fundamentally a political one" (McInerney $1987 a, b$ ).

\section{REFERENCES}

Anderson, R. M. \& Trewhella, W. (1985). Population dynamics of the badger (Meles meles) and the epidemiology of bovine tuberculosis (Mycobacterium bovis). Philosophical Transactions of the Royal Society of London, Series B 310, 327-381.

Bentil, D. E. \& Murray, J. D. (1993). Modelling bovine tuberculosis in badgers. Journal of Animal Ecology 62, 239-250.

Bourne, J. (2001). An epidemiological investigation into bovine tuberculosis. 3rd Report. London: Department of Environment, Food and Rural Affairs (DEFRA), (www.defra.gov.uk/animalh/tb/isg).

Clifton-Hadley, R. S., Wilesmith, J. W., Richards, M. S., Upton, P. \& Johnston, S. (1995). The occurrence of Mycobacterium bovis infection in cattle in and around an area subject to extensive badger (Meles meles) control. Epidemiology and Infection 114, 179-193.

Collins, J. D. (1997). Meat plant surveillance and its role in the eradication of tuberculosis in cattle. TB Investigation Unit Selected Papers 1996, pp. 55-59. Dublin: ERAD Board.

Delahay, R. J., Langton, S., Smith, G. C., CliftonHadley, R. S. \& Cheeseman, C. L. (2000). The spatiotemporal distribution of Mycobacterium bovis (bovine tuberculosis) infection in a high-density badger population. Journal of Animal Ecology 69, 428-441.

Dormandy, T. (1999). The White Death-A History of Tuberculosis. London: Hambledon.

Dunnet, G. M., Jones, D. M. \& McInerney, J. P. (1986). Badgers and Bovine Tuberculosis. London: HMSO.
Francis, J. (1947). Bovine Tuberculosis, pp. 89-125. London: Staples Press.

FrANCIS, J. (1958). Tuberculosis in Animals and Man. London: Cassel.

Gallagher, J. \& Clifton-Hadley, R. S. (2000). Tuberculosis in badgers; a review of the disease and its significance for other animals. Research Veterinary Science 69 , 203-217.

Hancox, M. (1995). Badgers and bovine tuberculosis: a reappraisal of aetiology and pathogenesis. Journal of Agricultural Science 125, 441-443.

Hancox, M. (1997). Bovine tuberculosis in badgers: a reappraisal of aetiology and pathogenesis. Letters in Applied Microbiology 24, 226-227.

Hancox, M. (1998). Of Bourne, badgers and a bovine 'TB alert'. Respiratory Medicine 93, 72-73.

Hancox, M. (1999). A critical reappraisal of transmission routes for bovine tuberculosis in cattle. Respiratory Medicine 93, 220-222.

Hancox, M. (2000a). Cattle tuberculosis schemes: control or eradication? Letters in Applied Microbiology 31, 87-93.

Hancox, M. $(2000 b)$. Cattle TB Crisis: cause and cure? In Badgers and Bovine TB: follow up, Report HC 92, Appendix 15. London: House of Commons Agricultural Committee.

Hancox, M. $(2000 c)$. Bovine TB alert. Respiratory Medicine 94, 919-920.

Hardie, R. M. \& Watson, J. M. (1992). Mycobacterium bovis in England and Wales: past, present and future. Epidemiology and Infection 109, 23-33. 
Krebs, J. (1997). Bovine Tuberculosis in Cattle and Badgers. London: MAFF.

Little, T. W. A., Swan, C., Thompson, H. V. \& Wilesmith, J. W. (1982). Bovine tuberculosis in domestic and wild mammals in an area of Dorset. II. The badger population, its ecology and tuberculosis status. Journal of Hygiene, Cambridge 89, 211-224.

McIlroy, S. G., Neill, S. D. \& McCracken, R. M. (1986). Pulmonary lesions and Mycobacterium bovis excretion from the respiratory tract of tuberculin reacting cattle. Veterinary Record 118, 718-721.

MCInerney, J. P. (1987a). Assessing the policy of badger control and its effect on the incidence of bovine tuberculosis. Proceedings of the Society of Veterinary Epidemiology Preventative Medicine 133-147.

MCInerney, J. P. (1987 b). Bovine tuberculosis and badgers technical, economic and political aspects of a disease control programme. Journal of Agricultural Society 66, $136-166$.

Neill, S. D., O’Brien, J. J. \& McCracken, R. M. (1988). Mycobacterium bovis in the anterior respiratory tracts in the heads of tuberculin-reacting cattle. Veterinary Record 122, $184-186$.

O'Boyle, I. (2000). Review of badger (Meles meles) research licences in 1999. TB Investigation Unit Selected Papers 1999, pp. 15-21. Dublin: ERAD Board.

O'Reilly, L. M. \& Daborn, C. J. (1995). The epidemiology of Mycobacterium bovis infections in animals and man: a review. Tubercle and Lung Disease 76 (Suppl. 1), 1-46.

Pritchard, D. G., Stuart, F. A., Wilesmith, J. W., Cheeseman, C. L., Brewer, J. I., Bode, R. \& Sayers, P. S. (1986). Tuberculosis in East Sussex: III. Comparison of post-mortem and clinical methods for the diagnosis of tuberculosis in badgers. Journal of Hygiene, Cambridge 97, 27-36.

Ruxton, G. D. (1996). The effects of stochasticity and seasonality on model dynamics: bovine tuberculosis in badgers. Journal of Animal Ecology 65, 495-500.

Smith, G. C., Richards, M. S., Clifton-Hadley, R. S. \& Cheeseman, C. L. (1995). Modelling bovine tuberculosis in badgers in England: preliminary results. Mammalia 59, $639-650$.

Smith, G. C., Cheeseman, C. L. \& Clifton-Hadley, R. S. (1997). Modelling the control of bovine tuberculosis in badgers in England: culling and the release of lactating females. Journal of Applied Ecology 34, 1375-1386.

Sмiтh, G. C. (2001). Models of Mycobacterium bovis in wildlife and cattle. Tuberculosis 81, 51-64.

Smith, G. C., Cheeseman, C. L., Clifton-Hadley, R. S. \& Wilkinson, D. (2001 a). A model of bovine tuberculosis in the badger (Meles meles): an evaluation of control strategies. Journal of Applied Ecology 38, 509-519.
Smith, G. C., Cheeseman, C. L., Wilkinson, D. \& CliftonHadley, R. S. (2001 $b$ ). A model of bovine tuberculosis in the badger (Meles meles), the inclusion of cattle and the use of a live test. Journal of Applied Ecology 38, 520-535.

Swinton, J., Tuyttens, F., MacDonald, D., Nokes, D. J., Cheeseman, C. L. \& Clifton-Hadley, R. S. (1997). A comparison of fertility control and lethal control of bovine tuberculosis in badgers: the impact of perturbation induced transmission. Philosophical Transactions of the Royal Society of London, Series B 352, 619-631.

Tuyttens, F. A. M. \& MacDonald, D. (1998). Fertility control: an option for non-lethal control of wild carnivores? Animal Welfare 7, 339-364.

Tuyttens, F. A. M., Delahay, R. J., MacDonald, D. W., Cheeseman, C. L., Long, B. \& Donnelly, C. A. (2000). Spatial perturbation caused by a badger culling operation: implications for the function of territoriality and the control of bovine tuberculosis (Mycobacterium bovis). Journal of Animal Ecology 69, 815-828.

White, P. C. L. \& Harris, S. (1995 a). Bovine tuberculosis in badger (Meles meles) populations in southwest England: the use of a spatial stochastic simulation model to understand the dynamics of the disease. Philosophical Transactions of the Royal Society of London, Series B 349, 391-413.

White, P. C. L. \& Harris, S. (1995 b). Bovine tuberculosis in badger (Meles meles) populations in southwest England: an assessment of past, present and future control strategies using simulation modelling. Philosophical Transactions of the Royal Society of London, Series B 349, 415-432.

White, P. W. \& Griffin, J. M. (1997). The disclosure of tuberculosis lesions after slaughter in cattle from attested herds in Co. Monaghan in 1994 and 1995. TB Investigation Unit Selected Papers 1996, pp. 64-71. Dublin: ERAD Board.

White, P. C. L., Lewis, A. J. G. \& Harris, S. (1997). Fertility control as a means of controlling bovine tuberculosis in badger (Meles meles) populations in southwest England: predictions from a spatial stochastic simulation model. Proceedings of the Royal Society of London, Series B 264, 1737-1747.

Wilesmith, J. (1991). Ecological and epidemiological findings from a prospective study of a naturally infected badger population. Symposium on TB. Veterinary Continuing Education, Massey University, Palmerston, New Zealand, pp. 89-111.

Woodroffe, R., Frost, S. D. W. \& Clifton-Hadley, R. S. (1999). Attempts to control tuberculosis in cattle by removing infected badgers: constraints imposed by live test sensitivity. Journal of Applied Ecology 36, 494-501.

Zuckerman, S. (1980). Badgers, Cattle and Tuberculosis. London: HMSO. 